Article

\title{
Compositional Optimization and Structural Properties of the Filled Skutterudite $\mathrm{Sm}_{y}\left(\mathrm{Fe}_{x} \mathrm{Ni}_{1-x}\right)_{4} \mathrm{Sb}_{11.5} \mathrm{Sn}_{0.5}$
}

\author{
Cristina Artini ${ }^{1,2, *}$, Riccardo Carlini ${ }^{1}$, Lara Gigli ${ }^{3}$ and Carlo Fanciulli ${ }^{4}$ \\ 1 Department of Chemistry and Industrial Chemistry, University of Genova, 16146 Genova, Italy; \\ riccardocarlini1@gmail.com \\ 2 Institute of Condensed Matter Chemistry and Technologies for Energy, National Research Council, \\ 16149 Genova, Italy \\ 3 Elettra-Sincrotrone Trieste S.C.p.A., 34149 Basovizza (Trieste), Italy; lara.gigli@elettra.eu \\ 4 Institute of Condensed Matter Chemistry and Technologies for Energy, National Research Council, \\ 23900 Lecco, Italy; carlo.fanciulli@cnr.it \\ * Correspondence: artini@chimica.unige.it; Tel.: +39-010-353-6082
}

Received: 9 May 2020; Accepted: 23 May 2020; Published: 25 May 2020

\begin{abstract}
A compositional and crystallographic study was carried out on the $\mathrm{Sm}_{y}\left(\mathrm{Fe}_{x} \mathrm{Ni}_{1-x}\right)_{4} \mathrm{Sb}_{11.5} \mathrm{Sn}_{0.5}$ filled skutterudite system $(0.40 \leq x \leq 0.80)$ with the aim to determine the equilibrium Sm filling fraction $(y)$ within the considered $x$ range. The relevance of the material lies in its potential thermoelectric properties: in analogy with similar skutterudites systems, these features should in fact result as being improved with respect to the ones of the corresponding Sn-free system thanks to the partial substitution of $\mathrm{Sn}$ for $\mathrm{Sb}$, which is expected to lower the phonon thermal conductivity. The results of Rietveld refinements allowed us to study the skutterudite structural properties and to discuss them, adopting a comparative approach with respect to the ones of the $\mathrm{Sn}$-free system $\mathrm{Sm}_{y}\left(\mathrm{Fe}_{x} \mathrm{Ni}_{1-x}\right)_{4} \mathrm{Sb}_{12}$. Relying on the refined Sm occupancy factors, the $p / n$ crossover is shown to be located at $x \sim 0.53$, meaning that the introduction of Sn induces an enlargement of the $p$-region; moreover, at variance with the Sn-free system, the coefficient of thermal expansion does not show any significant mismatch between $n$ - and $p$-compositions, which should ensure a prolonged lifetime of a device made of $n$ - and $p$-legs that both derive from the studied system.
\end{abstract}

Keywords: thermoelectrics; filled skutterudites; coefficient of thermal expansion; powder X-ray diffraction; Rietveld method; electron microscopy

\section{Introduction}

Filled skutterudites form a wide family of intermetallic compounds thoroughly studied for their potential thermoelectric properties [1-7]. They formally derive from skutterudites, binary compounds investigated for the first time by Oftedal in the first half of the last century [8]. Skutterudites have the general formula $\mathrm{MX}_{3}(\mathrm{M} \equiv \mathrm{Co}, \mathrm{Rh}, \mathrm{Ir}$, and $\mathrm{X} \equiv \mathrm{P}, \mathrm{As}, \mathrm{Sb})$ and crystallize in a body-centered cubic cell belonging to the $\operatorname{Im} \overline{3}$ space group; the atomic arrangement consists of two atomic positions, namely the $8 c(1 / 4,1 / 4,1 / 4)$ and the $24 g(0, y, z)$, which are occupied by the $\mathrm{M}$ and $\mathrm{X}$ atom, respectively. $\mathrm{M}$ is coordinated to $6 \mathrm{X}$ atoms forming strongly tilted octahedra. The parent compound $\mathrm{CoSb}_{3}$ does not present exploitable thermoelectric properties despite its high charge carrier mobility, due to its overly large thermal conductivity $\left(\lambda \sim 10 \mathrm{~W} \mathrm{~m}^{-1} \mathrm{~K}^{-1}\right.$ at $293 \mathrm{~K}$ [9]).

It is in fact well known that the optimization of a material's thermoelectric properties implies the maximization of the power factor $\sigma S^{2}$ and the minimization of $\lambda_{e}$ and $\lambda_{p h}$ (where $\sigma$ is the electrical conductivity, $S$ the Seebeck coefficient, and $\lambda_{e}$ and $\lambda_{p h}$ the electron and phonon thermal conductivity, respectively). This approach follows the phonon-glass electron-crystal (PGEC) concept [10], which states 
that the ideal thermoelectric material should conduct heat like a glass and electricity like a crystal. The maximization of $\sigma S^{2}$ results from the optimization of the charge carriers concentration, the increase of which at the same time causes an increase of $\sigma$ and a drop of $S$; it implies the knowledge of the material's band structure and its engineering. The reduction of $\lambda_{e}$, in turn, is limited by the Wiedemann-Franz law:

$$
\frac{\lambda_{e}}{\sigma}=L T
$$

where $L$ is the Lorenz number [11]. Therefore, the most convenient way to reduce thermal conductivity is the manipulation of $\lambda_{p h}$, which essentially consists in the introduction of scattering centers, such as interstitial and substitutional atoms, able to disturb the phonon propagation throughout the structure. The introduction of interstitial and substitutional atoms, as well as actions directed toward the modification of extrinsic factors, such as density enhancement [12-14], porosity control [15], nanostructuring [16], mesostructuring [17], or precipitation of nano-sized secondary phases [18], can be mentioned among the most effective methods to enhance phonon scattering, and hence to reduce $\lambda_{p h}$.

In the framework of the introduction of foreign atoms, and according to Slack's intuition [19], filling the $\mathrm{Sb}_{12}$ icosahedral cage formed in skutterudites around the $2 a$ position $(0,0,0)$ by a proper atom (mainly a lanthanide or an alkaline-earth element $[1,7,20]$ ) strongly reduces thermal conductivity, as testified by many filled skutterudite systems, such as for example $\mathrm{RE}_{0.1} \mathrm{Co}_{4} \mathrm{Sb}_{12}(\mathrm{RE} \equiv \mathrm{La}, \mathrm{Ce}, \mathrm{Nd}$, $\mathrm{Sm}, \mathrm{Yb}, \mathrm{Eu}$ ), which display much lower thermal conductivity values ranging between 3.5 and $5.5 \mathrm{~W}$ $\mathrm{m}^{-1} \mathrm{~K}^{-1}$ at $293 \mathrm{~K}$, depending on the rare earth identity [21]. Even more relevant results can be obtained when a double or a multiple filling of the $2 a$ position by different filler atoms is operated, such as in the case of the $(\mathrm{Sm}, \mathrm{Gd})_{y}\left(\mathrm{Fe}_{x} \mathrm{Ni}_{1-x}\right)_{4} \mathrm{Sb}_{12}$ [22], the (Ba,Sr,DD,Yb) $\left(\mathrm{Fe}_{x} \mathrm{Ni}_{1-x}\right)_{4} \mathrm{Sb}_{12}(\mathrm{DD} \equiv$ didymium, a Nd/Pr mixture) [23], the $\mathrm{Ce}_{x} \mathrm{Nd}_{x} \mathrm{Fe}_{3.7} \mathrm{Ni}_{0.3} \mathrm{Sb}_{12}$ [24], the $\mathrm{Mm}_{y}\left(\mathrm{Fe}_{x} \mathrm{Co}_{1-x}\right)_{4} \mathrm{Sb}_{12}(\mathrm{Mm} \equiv$ mischmetal, a natural mixture of $\mathrm{Ce}, \mathrm{La}, \mathrm{Pr}$, and $\mathrm{Nd}$ ) [25], and the $\mathrm{Ba}_{x} \mathrm{Yb}_{y} \mathrm{Co}_{4} \mathrm{Sb}_{12}$ systems [26]. When the transition metal is also partially substituted, additional phonon scattering is provided, and thermal conductivity is further reduced. Following this idea, a large variety of filled skutterudites containing two different transition metals were prepared and studied; even when limiting oneself to antimonides, several Fe/Ni [27-31], $\mathrm{Fe} / \mathrm{Co}$ [32-37], and Ni/Co [38-40] filled skutterudites systems are documented in the literature.

A third way aimed at introducing further disorder into the structure, and hence at reducing $\lambda$, involves the partial substitution of $\mathrm{Sb}$ at the $24 \mathrm{~g}$ site by various elements or element mixtures, such as Sn [32,33,41,42], Ge [32,43,44], Te [45], Se [46], Se/Te [46], Te/S [47], or Te/Sn [48]. Sn-doping, in particular, proved to be particularly effective at reducing phonon thermal conductivity, as testified by $\mathrm{DD}_{0.59} \mathrm{Fe}_{2.7} \mathrm{Co}_{1.3} \mathrm{Sb}_{11.8} \mathrm{Sn}_{0.2}$ [32], as well as by $\mathrm{Ce}_{y} \mathrm{Co}_{4} \mathrm{Sb}_{12-\delta} \mathrm{Sn}_{\delta}$ [42], $\mathrm{Nd}_{0.6} \mathrm{Fe}_{2} \mathrm{Co}_{2} \mathrm{Sb}_{12-\delta} \mathrm{Sn}_{\delta}$ [41], and $\mathrm{CoSb}_{3-\delta} \mathrm{Sn}_{\delta}$ [49]. The positive effect occurs despite the closeness of $\mathrm{Sn}$ and $\mathrm{Sb}$ atomic masses, which makes mass fluctuation scattering negligible.

The partial substitution of $\mathrm{Sb}$ by an aliovalent atom also exerts an effect on the electronic properties of the material. Even without resorting to band structure calculations, skutterudites can be described through Zintl's approach, which allows one to explain the diamagnetic and semiconducting nature of $\mathrm{CoSb}_{3}[1,7]$. The substitution of $\mathrm{Co}$ by a Fe/Ni mixture induces an electron imbalance, which can be only partly restored by the injection of electrons from the filler: it is in fact well known that the filling fraction is an intrinsic property of a given skutterudite system [1], also affecting the structural properties of the material [50], and that a different filler amount can hardly be forced into the structure [27] unless drastic techniques are used, such as synthesis at a high [14] or extremely high pressure [51]. Consequently, $p$ - and $n$-conducting skutterudites occur; in the $\mathrm{Sm}_{y}\left(\mathrm{Fe}_{x} \mathrm{Ni}_{1-x}\right)_{4} \mathrm{Sb}_{12}$ system, for example, the $p / n$ crossover is located at $x \sim 0.63$ [29]. It can thus be expected that the partial substitution of $\mathrm{Sb}$ by $\mathrm{Sn}$, namely by an atom with an electron that is less in the outer shell, requires the insertion of a larger number of electrons deriving from the filler to reach the electron count of a degenerate semiconductor. Nevertheless, since the introduction of filler atoms does not generally satisfy the requirement for a degenerate semiconductor for the aforementioned reasons, it can be expected that $\mathrm{Sn} / \mathrm{Sb}$-based skutterudites are characterized by a larger $p$-compositional extent than the Sb-based ones, 
as indeed verified for $\mathrm{CoSb}_{3-\delta} \mathrm{Sn}_{\delta}$, where the $\mathrm{Sb}$ substitution by $\mathrm{Sn}$ was in fact originally employed to obtain $p$ - $\mathrm{CoSb}_{3}$ [52].

Following the idea of increasing the disorder degree of the structure, the $\mathrm{Sm}_{y}\left(\mathrm{Fe}_{x} \mathrm{Ni}_{1-x}\right)_{4} \mathrm{Sb}_{11.5} \mathrm{Sn}_{0.5}$ filled skutterudite was taken into consideration, as it derives from the $\mathrm{Sm}_{y}\left(\mathrm{Fe}_{x} \mathrm{Ni}_{1-x}\right)_{4} \mathrm{Sb}_{12}$ system, which was thoroughly studied by the present research group [53-61] for its promising thermoelectric properties, which provide $Z T=0.55$ at $\sim 600 \mathrm{~K}$ [62]. As aforementioned, the filling fraction is of primary importance in driving the electronic properties of a filled skutterudite; nevertheless, its equilibrium value can hardly be predicted a priori, and the issue needs to be fixed in the first stages of the study of a new system to ensure the preparation of pure samples. A preliminary work of compositional optimization was thus undertaken on the chosen system: in the absence of literature data, experimental $y$ values found for each $x$ in the $\mathrm{Sm}_{y}\left(\mathrm{Fe}_{x} \mathrm{Ni}_{1-x}\right)_{4} \mathrm{Sb}_{12}$ system [29] were employed for the synthesis of Sn-containing samples. A subsequent compositional and structural study was performed in order to reveal the actual Sm content of specimens, and ultimately to optimize the synthesis procedure.

Moreover, a further technologically relevant issue when dealing with a thermoelectric material concerns its coefficient of thermal expansion (CTE). Ideally, the CTE mismatch between the $n$ - and $p$-leg of a thermoelectric device should be as small as possible, in order to reduce the thermal stress caused by the uninterrupted work under large temperature gradients, and therefore to prolong the device lifetime. It is generally meant for this goal to be reached if both the $p$ - and the $n$-elements derive from the same matrix [63]; nevertheless, the issue is not obvious, and this prediction is only confirmed in some cases, such as for the (Ba,DD, $\mathrm{Yb}, \mathrm{Sr})_{y} \mathrm{Fe}_{3} \mathrm{NiSb}_{12}$ system [23]. In most skutterudite systems, on the contrary, CTE is shown to be higher for $p$ - than in $n$-compositions $[63,64]$, so that Rogl et al. proposed for instance the dispersion of nano-sized $\mathrm{Ta}_{0.8} \mathrm{Zr}_{0.2} \mathrm{~B}$ particles into a $(\mathrm{Mm}, \mathrm{Sm})_{y} \mathrm{Co}_{4} \mathrm{Sb}_{12}$ matrix to reduce the $n / p$ CTE mismatch [65]. In this respect, an interesting case is represented by $\mathrm{Sm}_{y}\left(\mathrm{Fe}_{x} \mathrm{Ni}_{1-x}\right)_{4} \mathrm{Sb}_{12}$, which displays a significant $p / n$ CTE mismatch [61], as a consequence of the discontinuity occurring at the $p / n$ crossover in the lattice parameter trend vs. the Fe content [29]. In the present work, crystallographic data collected up to $773 \mathrm{~K}$ were employed to determine the $\mathrm{Sm}_{y}\left(\mathrm{Fe}_{x} \mathrm{Ni}_{1-x}\right)_{4} \mathrm{Sb}_{11.5} \mathrm{Sn}_{0.5} \mathrm{CTE}$, which revealed a much lower $p / n$ mismatch and thus a very promising mechanical behavior.

\section{Materials and Methods}

\subsection{Synthesis}

Four compositions belonging to the $\mathrm{Sm}_{y}\left(\mathrm{Fe}_{x} \mathrm{Ni}_{1-x}\right){ }_{4} \mathrm{Sb}_{11.5} \mathrm{Sn}_{0.5}$ system $(x=0.40$ and $y=0.06$; $x=0.55$ and $y=0.23 ; x=0.60$ and $y=0.31 ; x=0.80$ and $y=0.55$ ) were prepared via the conventional melting-quenching-annealing technique commonly used for the Sn-free system [29,61]; in the absence of specific literature data, the Sm amount $(y)$ to be added in association to each $x$ value was chosen to be identical to the experimental value observed in the $\mathrm{Sm}_{y}\left(\mathrm{Fe}_{x} \mathrm{Ni}_{1-x}\right)_{4} \mathrm{Sb}_{12}$ system [29]. The starting materials were stoichiometric amounts of Fe (Alfa-Aesar, Kandel, Germany, 99.99 wt. \%), Ni (Alfa-Aesar, Kandel, Germany, 99.99 wt. \%), Sm (NewMet, Waltham Abbey, UK, 99.9 wt. \%), and pre-alloyed $\mathrm{Sb}_{0.96} \mathrm{Sn}_{0.04}$. The precursor alloy, in turn, was prepared from due amounts of $\mathrm{Sb}$ (Mateck, Jülich, Germany, 99.99 wt. \%) and Sn (Sigma Aldrich, Darmstadt, Germany, 99.99 wt. \%) by melting the proper mixture at $903 \mathrm{~K}$ in a quartz vial sealed under Ar gas $(\mathrm{P}=80 \mathrm{KPa})$. Materials were mixed and placed into a quartz tube, which was evacuated, closed, and heated up to $1238 \mathrm{~K}$, and then rapidly cooled to obtain microcrystalline phases that can be easily decomposed in favor of the filled skutterudite during the subsequent annealing treatment. In addition, the rapid cooling of the liquid phase prevents the formation of the $\left(\mathrm{Fe}_{x} \mathrm{Ni}_{1-x}\right) \mathrm{Sb}$ phase, which is stable at high temperature and does not evolve into the filled skutterudites at the annealing temperature. Samples were then annealed under vacuum at $873 \mathrm{~K}$ for ten days, and afterwards slow-cooled. Samples were named Fe40_303, Fe55_373, and so on, where the first number stands for the $\mathrm{Fe} \%$ amount with respect to the overall $(\mathrm{Fe}+\mathrm{Ni})$ content, and the second one stands for the temperature in $\mathrm{K}$ which the diffraction pattern was collected at. 


\subsection{Scanning Electron Microscopy-Energy-Dispersive X-Ray Spectroscopy (SEM-EDS)}

Samples were cut in pieces to be micrographically polished prior to the observation by electron microscopy coupled to an energy dispersive system (Zeiss LEO 1430, Jena, Germany, equipped with EDS INCA Energy 200, Link Analytical-Oxford Instruments, Abingdon-on-Thames, UK). By this technique, the occurrence of phases was studied, and their composition was evaluated. Microphotographs were taken both by backscattered and secondary electrons, and EDS analyses were performed on at least five points for each sample.

\subsection{High Temperature Powder X-ray Diffraction}

The room and high temperature structural properties of all the samples were studied by a Bragg-Brentano powder diffractometer (PANalytical X'pert Pro, Almelo, The Netherlands, $\mathrm{Cu}$ K $\alpha$ radiation); Ge was used as an internal standard to accurately determine the skutterudite lattice parameter of each specimen. Samples were crushed, ground, sieved through a $75 \mu \mathrm{m}$ sieve, placed on an alumina sample-holder, and introduced into a high temperature oven chamber (Anton Paar, HTK 1200N, Graz, Austria); diffraction patterns were collected at room temperature ( $303 \mathrm{~K})$, as well as at $373,473,573$, 673 , and $773 \mathrm{~K}$ (angular range: $10-112^{\circ}$, step $0.017^{\circ}$, time per step: $90 \mathrm{~s}$ ). Samples were protected from oxidation by He atmosphere. The structural models of skutterudite and, when possible, of extra phases, were refined for samples Fe40, Fe55, and Fe60 by the Rietveld method through the FullProf software, version September 2020 [66]. Due to the large content of extra phases, it was not possible to refine the skutterudite structural model of sample Fe80. On the contrary, the skutterudite cell parameter was calculated for all the compositions by the least squares method. To this purpose, the Ge CTE was found by collecting the diffraction patterns of Ge at the same temperatures as the samples, and by refining the Ge lattice parameter. The CTE values resulting at the different temperatures for Ge were found in good agreement with literature data [67], and were employed to calculate the Ge cell parameter at each temperature; the cell parameter $a=5.6575 \AA$ [67] was used as the room temperature reference value.

\section{Results}

\subsection{Compositional and Morphological Characterization}

SEM microphotographs indicate that in all the samples, except in Fe80, the filled skutterudite is the main phase; nevertheless, even other phases are present: in particular, three differently colored regions appear in Figure 1. Relying on EDS analyses, the darkest one consists of $(\mathrm{Fe}, \mathrm{Ni}) \mathrm{Sb}_{2}$, the lightest one of $\mathrm{Sb}_{1-x} \mathrm{Sn}_{x}$, and the intermediate one of the Sn-containing skutterudite. Moreover, the observation of Figure 1 also suggests that Fe55 is essentially formed of skutterudite, the amount of extra phases being almost negligible (see Figure $1 \mathrm{~b}$ ), and that Fe80 is mainly composed of $\mathrm{Sb}_{1-x} \mathrm{Sn}_{x}$ and (Fe,Ni)Sb .
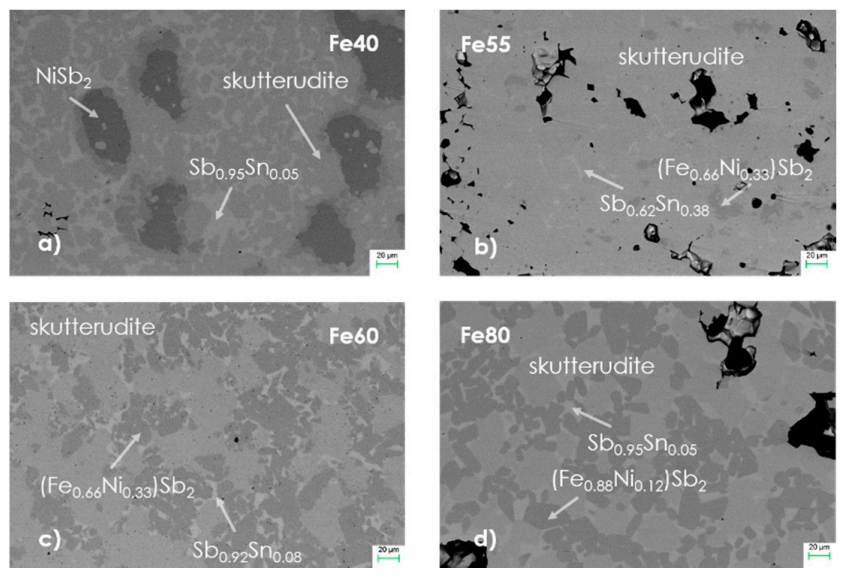

Figure 1. SEM microphotographs taken by backscattered electrons on the polished surface of the samples (a) Fe40, (b) Fe55, (c) Fe60, and (d) Fe80. 
The results of the room temperature X-ray diffraction analyses confirm the outcome of the electron microscopy while revealing the presence of tiny amounts of other extra phases, such as for example $\mathrm{SbSn}$. An overview of the compositional analyses of all the samples is provided in Table 1; the amounts of extra phases whose structural models could be refined are reported too. The amount of additional phases in Fe80 was not quantified due to the impossibility to refine the structural models of phases contributing to the sample.

Similarly to Sn-free skutterudites [22], even the present samples present a high porosity degree, as observable in Figure 2, where microphotographs taken by secondary electrons are collected.
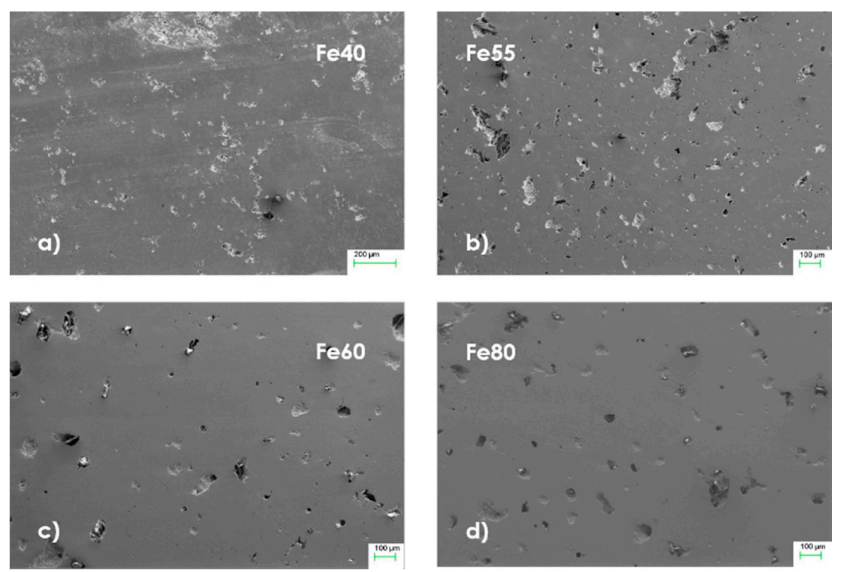

Figure 2. SEM microphotographs taken by secondary electrons on the polished surface of the samples (a) Fe40, (b) Fe55, (c) Fe60, and (d) Fe80.

Table 1. Refined composition, amount of additional phases as revealed by EDS and X-ray diffraction, skutterudite cell parameter, and Rietveld agreement factors for each sample. Sample Fe80 is mainly composed of the extra phases $\mathrm{Sb}$ and $\mathrm{FeSb}_{2}$.

\begin{tabular}{|c|c|c|c|c|c|}
\hline Sample & Refined Composition & $\begin{array}{c}\text { Additional Phases } \\
\text { (wt. } \%)\end{array}$ & $\begin{array}{c}\text { Skutterudite } a \\
\text { Cell Parameter } \\
{[\AA ̊]}\end{array}$ & $\chi^{2^{1}}$ & Skutterudite $R_{B}{ }^{2}$ \\
\hline Fe40_303 & \multirow{6}{*}{$\mathrm{Sm}_{0.22}\left(\mathrm{Fe}_{0.41} \mathrm{Ni}_{0.59}\right)_{3.9} \mathrm{Sb}_{11.8} \mathrm{Sn}_{0.2}$} & \multirow{6}{*}{$\mathrm{Sb}_{0.95} \mathrm{Sn}_{0.05}(11 \%)$} & $9.0948(1)$ & 18.5 & 9.39 \\
\hline $\mathrm{Fe} 40 \_373$ & & & $9.1023(1)$ & 15.0 & 9.91 \\
\hline Fe40_473 & & & $9.1128(1)$ & 12.5 & 10.5 \\
\hline Fe40_573 & & & $9.1245(1)$ & 12.7 & 9.43 \\
\hline Fe40_673 & & & $9.1370(1)$ & 12.1 & 11.0 \\
\hline Fe40_773 & & & $9.1487(1)$ & 12.8 & 9.88 \\
\hline Fe55_303 & \multirow{6}{*}{$\mathrm{Sm}_{0.26}\left(\mathrm{Fe}_{0.55} \mathrm{Ni}_{0.45}\right)_{3.7} \mathrm{Sb}_{11.5} \mathrm{Sn}_{0.5}$} & \multirow{6}{*}{$\begin{array}{c}\mathrm{Fe}_{0.66} \mathrm{Ni}_{0.33} \mathrm{Sb}_{2} \\
\text { (traces); } \mathrm{SbSn} \\
\text { (traces) }\end{array}$} & $9.1004(1)$ & 7.30 & 6.44 \\
\hline Fe55_373 & & & $9.1085(1)$ & 6.85 & 6.11 \\
\hline Fe55_473 & & & $9.1203(1)$ & 7.63 & 6.18 \\
\hline Fe55_573 & & & $9.1326(1)$ & 6.58 & 6.19 \\
\hline Fe55_673 & & & $9.1457(1)$ & 5.81 & 5.79 \\
\hline Fe55_773 & & & $9.1585(1)$ & 6.03 & 5.18 \\
\hline Fe60_303 & \multirow{6}{*}{$\mathrm{Sm}_{0.27}\left(\mathrm{Fe}_{0.59} \mathrm{Ni}_{0.41}\right)_{3.7} \mathrm{Sb}_{11.7} \mathrm{Sn}_{0.3}$} & \multirow{6}{*}{$\begin{array}{c}\mathrm{Sb}_{0.92} \mathrm{Sn}_{0.08}(9 \%) \\
\mathrm{Fe}_{0.66} \mathrm{Ni}_{0.33} \mathrm{Sb}_{2} \\
(29 \%)\end{array}$} & $9.1005(1)$ & 8.39 & 8.26 \\
\hline Fe60_373 & & & $9.1086(1)$ & 8.03 & 9.26 \\
\hline Fe60_473 & & & $9.1203(1)$ & 7.27 & 7.48 \\
\hline Fe60_573 & & & $9.1322(1)$ & 6.08 & 7.90 \\
\hline Fe60_673 & & & 9.1453(1) & 6.90 & 8.25 \\
\hline Fe60_773 & & & 9.1573(1) & 4.66 & 5.14 \\
\hline Fe80_303 & \multirow{6}{*}{$\mathrm{Sm}_{0.61}\left(\mathrm{Fe}_{0.79} \mathrm{Ni}_{0.21}\right)_{3.9} \mathrm{Sb}_{11.8} \mathrm{Sn}_{0.2}$} & \multirow{6}{*}{$\begin{array}{c}\mathrm{Sb} ; \mathrm{FeSb}_{2} \\
\mathrm{SbSn} \text { (traces) }\end{array}$} & $9.1181(1)$ & - & - \\
\hline Fe80_373 & & & $9.1267(1)$ & - & - \\
\hline Fe80_473 & & & $9.1392(1)$ & - & - \\
\hline Fe80_573 & & & $9.1508(1)$ & - & - \\
\hline Fe80_673 & & & $9.1661(1)$ & - & - \\
\hline Fe80_773 & & & $9.1831(1)$ & - & - \\
\hline
\end{tabular}




\subsection{Structural Characterization}

The skutterudite structural model was refined by the Rietveld method for the samples Fe40, Fe55, and Fe60 according to the previously described cubic cell crystallizing in the $\operatorname{Im} \overline{3}$ space group. For each diffraction pattern, in the last refinement cycles the structural parameters ( $y$ and $z$ atomic coordinates of $\mathrm{Sb}$, and the $\mathrm{Sm}$ occupancy factor of the $2 a$ position), as well as the scale factor, nine peak parameters (U, V, W, $\eta$ [the Gaussian/Lorentzian mixing parameter], $Y$ [the $\theta$ dependence of $\eta$ ], and four asymmetry parameters), and the background points were refined. The background was fitted by linear interpolation of a set of $\sim 70$ points taken from the experimental pattern, and the peak profiles were optimized by the pseudo-Voigt function. The Fe and Ni occupancy factors were fixed to the value obtained from the EDS analyses, due to the closeness of their atomic scattering factors. The $(\mathrm{Sb}+\mathrm{Sn})$ occupancy factor was constrained at 1 , relying on the EDS results, which indicate a $(\mathrm{Sb}, \mathrm{Sn}) /(\mathrm{Fe}, \mathrm{Ni})$ amount ratio slightly higher than 3 for each composition. The Sm occupancy factor, on the contrary, was refined for all the compositions at each temperature considered, being a reliable and critical parameter in the compositional optimization of the studied system. Angular regions corresponding to Ge peaks were excluded from the refinements. In Figure 3, the Rietveld refinement plot of sample Fe55_373 is reported as a representative example; a small peak attributable to an unknown compound is marked with an asterisk. The agreement factors $\left(\chi^{2}\right.$ and the skutterudite $\left.R_{B}\right)$, as well as the skutterudite cell parameters, can be found in Table 1 ; the refinement plots of all the samples at each temperature considered are reported as Supplementary Materials.

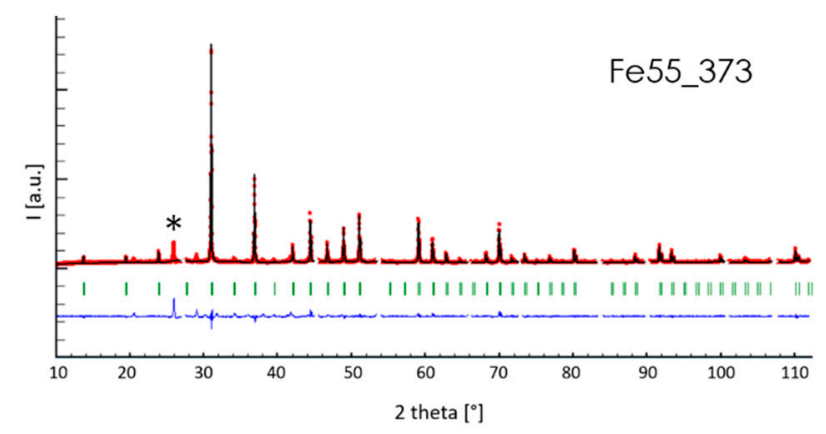

Figure 3. Rietveld refinement plot of sample Fe55_373. The red and black lines are the experimental and the calculated diffractograms, respectively; the lower blue line is the difference curve; green vertical bars indicate the calculated positions of Bragg peaks of the filled skutterudite; the asterisk indicates the presence of a small amount of an unknown compound. Angular regions corresponding to the positions of Ge peaks were excluded.

The skutterudite cell parameter linearly increases along the whole considered temperature span, as shown in Figure 4: the data can be excellently fitted by regression lines, as reported in Table 2, where the equations of the regression lines, as well as the corresponding $R^{2}$ value, are collected. A more detailed data analysis indicates that the expected value of the skutterudite cell parameter $a$ is very close to the experimental one; the goodness of the fit is further confirmed by the $R^{2}$ value. The slightly lower $R^{2}$ value of Fe80 is due to the presence of extra phases within the sample, which does not allow a more accurate determination of the cell parameter. 


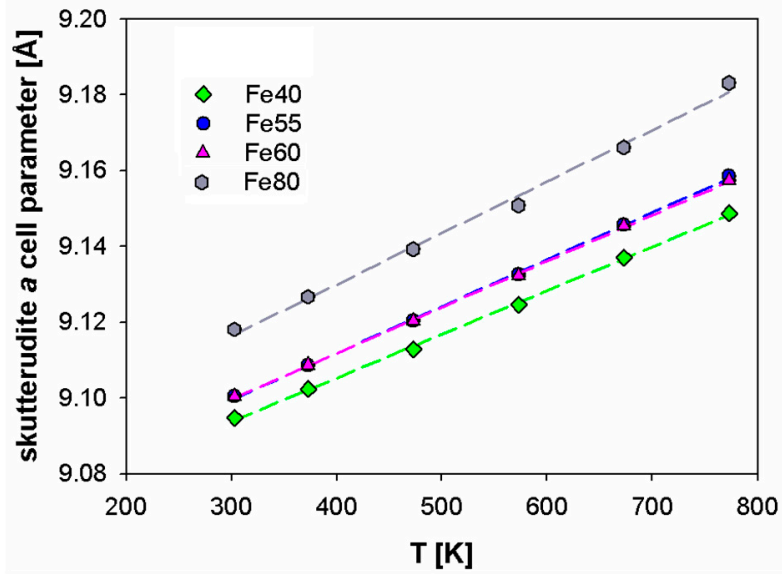

Figure 4. Trend of the skutterudite $a$ cell parameter as a function of the temperature for each sample. The dashed lines are the regression lines fitting the experimental points; the error bars are hidden by data markers.

Table 2. Equation of the regression lines $a=\mathrm{m} T+\mathrm{q}$ fitting the $a$ lattice parameter vs. the temperature $(T)$ for each composition; the expected $a$ values at $303 \mathrm{~K}$ and the calculated $R^{2}$ values are reported too.

\begin{tabular}{cccc}
\hline Sample & Equation of the Regression Line & $\begin{array}{c}\text { Expected a Value } \\
\text { at 303 K [̊̊] }\end{array}$ & $\boldsymbol{R}^{2}$ \\
\hline Fe41 & $a=1.1520 \times 10^{-4} T+9.0592$ & 9.0941 & 0.999 \\
Fe55 & $a=1.2370 \times 10^{-4} T+9.0623$ & 9.0998 & 0.999 \\
Fe59 & $a=1.2135 \times 10^{-4} T+9.0633$ & 9.1001 & 0.999 \\
Fe79 & $a=1.3595 \times 10^{-4} T+9.0756$ & 9.1168 & 0.994 \\
\hline
\end{tabular}

The Sm occupancy factor is a crucial parameter in the study of the structural and electronic properties of filled skutterudites, as described in the Introduction and discussed in more detail in the following section. Moreover, the high atomic number of the element allows a reliable determination of its occupancy factor. In Figure 5, the trend of the Sm occupancy factor in the $2 a$ site as a function of the temperature is reported for each sample, revealing a roughly linear increase.

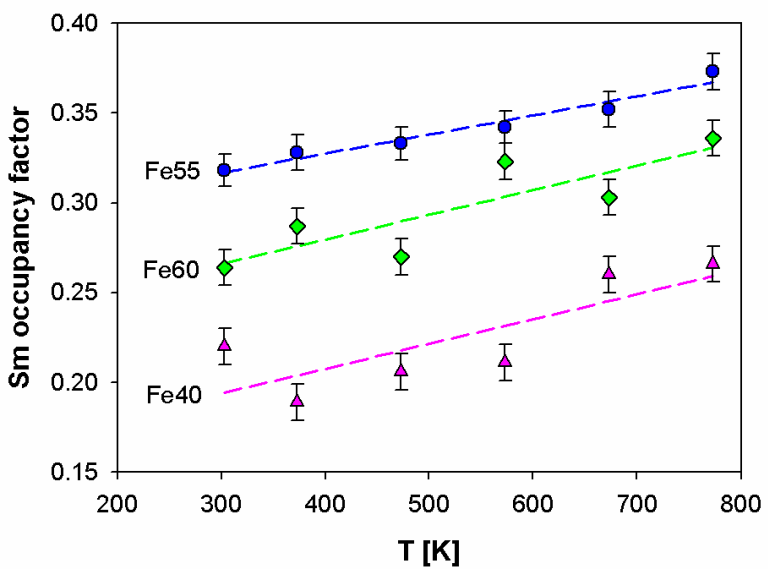

Figure 5. Trend of the Sm occupancy factor in the $2 a$ site as a function of the temperature for each sample. The dashed lines are the regression lines fitting the experimental points.

\section{Discussion}

The position of the $p / n$ crossover in filled skutterudites can be at least roughly determined, relying on the simple bonding model adopted in the framework of the Zintl's concept. According to this approach, 
$\mathrm{CoSb}_{3}$, and also the isoelectronic $\mathrm{Fe}_{0.5} \mathrm{Ni}_{0.5} \mathrm{Sb}_{3}$, are degenerate semiconductors, as experimentally confirmed [1]. Filling the cavity located in $(0,0,0)$ with an electropositive element introduces a certain number of electrons per filler atom, which tend to fix the electron imbalance; nevertheless, filler atoms generally introduce excessive holes or excessive electrons, thus giving rise to $p$ - and $n$-skutterudites, respectively. A convenient graphical method highlighting the position of the crossover in the $\mathrm{Sm}_{y}\left(\mathrm{Fe}_{x} \mathrm{Ni}_{1-x}\right)_{4} \mathrm{Sb}_{12}$ system consists in reporting two lines in a $y$ vs. $x$ diagram: the one representing the Sm amount theoretically necessary to exactly reproduce the electronic count of the parent compound $\mathrm{CoSb}_{3}$, and the one fitting the experimental $y$ data corresponding to each $x$ value. The crossing point of the two lines can be considered as the $p / n$ crossover, as revealed by the structural data. In Figure 6, the thick and thin dash-dot green lines represent the ideal and the regression lines, respectively, for the $\mathrm{Sm}_{y}\left(\mathrm{Fe}_{x} \mathrm{Ni}_{1-x}\right)_{4} \mathrm{Sb}_{12}$ system: as aforementioned, the $p / n$ crossover is located at $x \sim 0.63$, as indeed confirmed by the room temperature Seebeck measurements [29]. When $\mathrm{Sb}$ is partly substituted by an element with an electron that is less in the outer shell, such as $\mathrm{Sn}$, fewer electrons are provided for the skutterudite bonding scheme and more electrons are required from the filler to fix the electron imbalance; as a consequence, the ideal line moves toward higher $y$ values, meaning that higher Sm amounts are necessary to reproduce the electron count of a compensated semiconductor. This scenario is evident in Figure 6, where the thick dashed blue line represents the ideal line for the $\mathrm{Sm}_{y}\left(\mathrm{Fe}_{x} \mathrm{Ni}_{1-x}\right)_{4} \mathrm{Sb}_{11.5} \mathrm{Sn}_{0.5}$ system. The blue points appearing within the diagram represent the refined $y$ values of this system. Two main issues are worth noting: first of all, experimental $y$ values can be satisfactorily fitted by a line, similarly to the $\mathrm{Sn}$-free system. This evidence allows one to localize the crossing point of the two lines, and hence the $p / n$ crossover, which results in being located at $x \sim 0.53$, thus confirming the expectation for a larger $p$-region with respect to the Sn-free system.

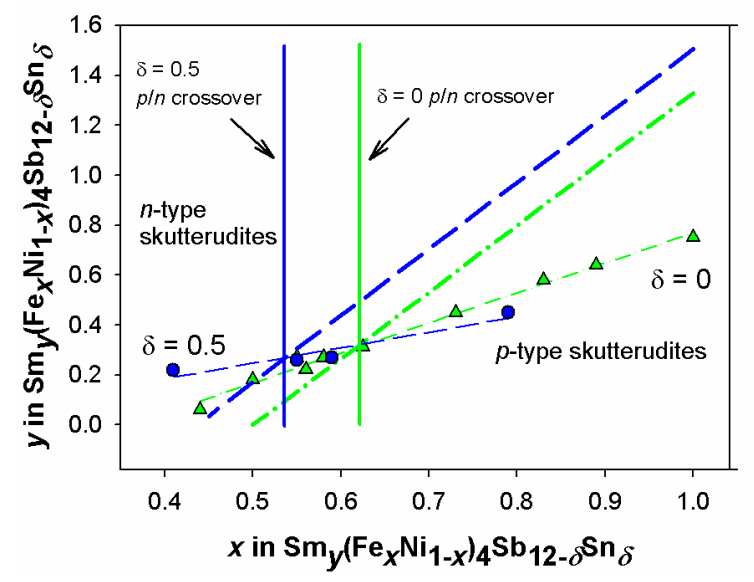

Figure 6. Sm content $(y)$ in $\mathrm{Sm}_{y}\left(\mathrm{Fe}_{x} \mathrm{Ni}_{1-x}\right)_{4} \mathrm{Sb}_{12-\delta}$ filled skutterudites as a function of $\mathrm{x}$. The thick dash-dot green and dashed blue lines represent the theoretical $\mathrm{Sm}$ amount necessary to reproduce the electronic count of a compensated semiconductor in the $\mathrm{Sm}_{y}\left(\mathrm{Fe}_{x} \mathrm{Ni}_{1-x}\right)_{4} \mathrm{Sb}_{12}$ and $\mathrm{Sm}_{y}\left(\mathrm{Fe}_{x} \mathrm{Ni}_{1-x}\right)_{4} \mathrm{Sb}_{11.5} \mathrm{Sn}_{0.5}$ systems, respectively; the thin ones are the regression lines interpolating experimental points; vertical lines highlight the position of the $p / n$ crossover for both systems. Error bars are hidden by data markers; the data of the $\mathrm{Sm}_{y}\left(\mathrm{Fe}_{x} \mathrm{Ni}_{1-x}\right)_{4} \mathrm{Sb}_{12}$ system are taken from ref. [29].

Secondly, the samples Fe 40 and Fe 80 are characterized by $y$ values quite far from the ones typical of the $\mathrm{Sm}_{y}\left(\mathrm{Fe}_{x} \mathrm{Ni}_{1-x}\right)_{4} \mathrm{Sb}_{12}$ system. The latter outcome is the reason why both cited samples are polyphasic and also provides a clear indication toward the synthesis of monophasic samples, which is essential for reliable measurements of the skutterudite transport properties. This conclusion is confirmed by the substantial monophasicity of sample Fe55, which presents a refined $y$ very close to the one of the composition with the same Fe content in the Sn-free system.

The analysis of microphotographs taken at a higher magnification by backscattered electrons on polyphasic samples also suggests the skutterudite formation mechanism. It is known that after 
the melting-quenching stage, leading to $(\mathrm{Fe}, \mathrm{Ni}) \mathrm{Sb}_{2}$ and $\mathrm{Sb}$ [55], the subsequent annealing treatment promotes the formation of the filled skutterudite. The image of sample Fe80 shown in Figure 7 confirms that the skutterudite formation occurs by a reaction between (Fe,Ni)Sb ${ }_{2}$ and $\mathrm{Sb}_{1-x} \mathrm{Sn}_{x}$, and that it stops before the complete consumption of the reacting alloys, most probably due to the incorrect Sm amount.

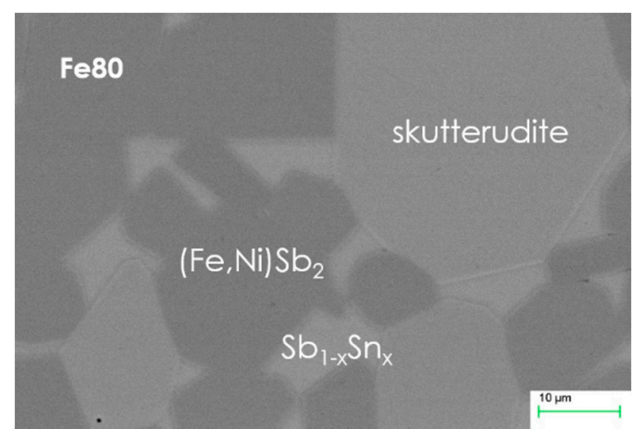

Figure 7. SEM microphotograph taken by secondary electrons on the polished surface of sample Fe80.

Despite the presence of different amounts of additional phases, the results of the Rietveld refinements on the filled skutterudite (performed on Fe40, Fe55, and Fe60), as well as of the cell parameters determination at each temperature (performed on all the samples), reveal intriguing characteristics of the skutterudite structure, especially when compared to the ones of the Sn-free system $\mathrm{Sm}_{y}\left(\mathrm{Fe}_{x} \mathrm{Ni}_{1-x}\right)_{4} \mathrm{Sb}_{12}$.

In Figure 8, the trend of the skutterudite cell parameter $a$ is reported as a function of the Fe content $(x)$ at each considered temperature. For the sake of comparison, the cell parameter of the Sn-free system at room temperature is also reported. Again, two main issues can be noticed. Firstly, the cell parameters values indirectly confirm that Sn indeed entered the skutterudite structure, since for each composition they are larger than the corresponding ones of the Sn-free system, as a direct consequence of the larger size of $\mathrm{Sn}^{4-}(2.94 \AA)$ [49] with respect to $\mathrm{Sb}^{5-}(2.45 \AA)$ [49]. A further confirmation of this conclusion comes from the analysis of the $\mathrm{Sm}-\mathrm{Sb} / \mathrm{Sn}$ interatomic distance, which can be considered as the size of the cavity centered on the $2 a$ site: as evidenced in Figure 9, at each temperature the cited distance is larger for the Sn-containing than for the Sn-free skutterudite. The observed increase in the interatomic distance with an increasing temperature is also in good agreement with the slight increase in the Sm occupancy factor with a rising temperature observed in all the analyzed samples (Fe40, Fe55, and Fe60) and reported in Figure 5. A strict correlation between the cage size and the filler content was previously demonstrated [29].

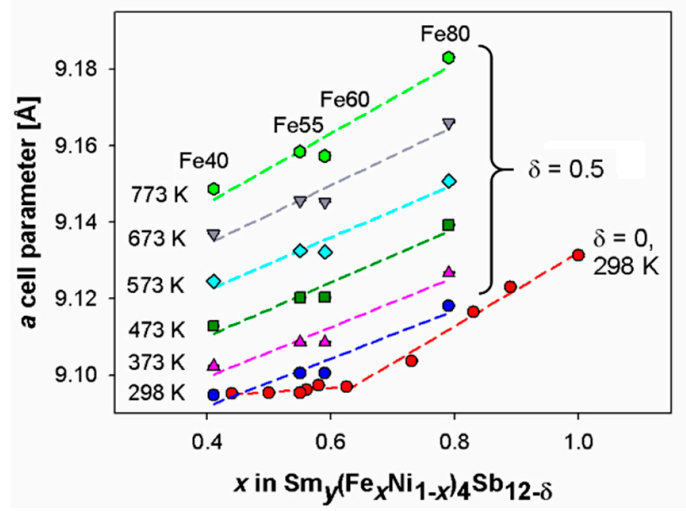

Figure 8. Trend of the $a$ lattice parameter as a function of the Fe content $(x)$ at each temperature; the room temperature values for the $\mathrm{Sm}_{y}\left(\mathrm{Fe}_{x} \mathrm{Ni}_{1-x}\right)_{4} \mathrm{Sb}_{12}$ system (red circles), taken from ref. [29], are also reported as a term of comparison. 


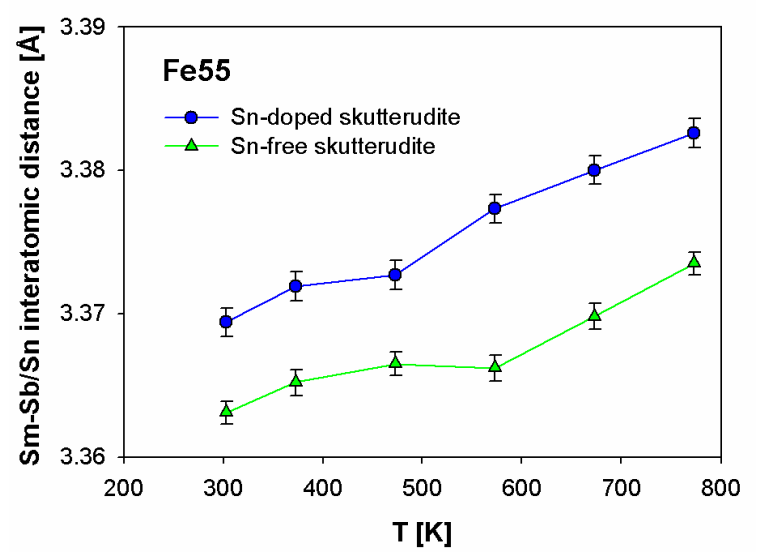

Figure 9. Trend of the $\mathrm{Sm}-\mathrm{Sb}$ interatomic distances as a function of the temperature for the sample Fe55 of the Sn-containing and the Sn-free skutterudite systems; the data of the latter are taken from ref. [61]. The dashed lines are regression lines.

Secondly, the observation of Figure 8 suggests that the slope change occurring in the trend of the cell parameter of the Sn-free system in correspondence of the $p / n$ crossover, widely discussed in $[29,61]$ and possibly attributed to a low/high spin transition of $\mathrm{Fe}^{2+}$, seems to be absent from the Sn-containing one.

The coefficient of linear thermal expansion (CTE) is defined in a certain temperature range as:

$$
C T E=\frac{1}{a_{T_{0}}} \frac{\left(a_{T}-a_{T 0}\right)}{T-T_{0}}
$$

with $a_{T_{0}}$ being the cell parameter at the reference temperature $T_{0}\left(T_{0}=303 \mathrm{~K}\right.$ in this work). Due to the excellent linearity of the skutterudite cell parameters vs. temperature along the considered temperature range (see Table 1), only one CTE was calculated for each composition. The obtained CTE values are reported in Figure 10 as a function of the composition, together with the ones of the Sn-free system, taken from [61]. In good agreement with the aforementioned lacking slope change in the cell parameter vs. $x$ shown in Figure 8, even the CTE trend shows no discontinuity in the Sn-containing samples; on the contrary, in the $\mathrm{Sn}$-free system $\mathrm{Sm}_{y}\left(\mathrm{Fe}_{x} \mathrm{Ni}_{1-x}\right)_{4} \mathrm{Sb}_{12}$, a 16\% CTE mismatch between samples with $x=0.55$ and $x=0.63$ occurs [61]. This is quite an important and promising point, since a small CTE mismatch between $n$ - and $p$-compositions is of primary importance in the design of thermoelectric devices with $n$ - and $p$-legs deriving from the same matrix. The data reported in Figure 10 thus suggest that the employment of an Sn-containing $n$-composition and an Sn-free $p$-composition could conveniently build the $n$ - and the $p$-leg of a thermoelectric device made of the same skutterudite matrix having virtually identical CTE values. The described result assumes a remarkable significance because most of the skutterudite CTE values reported in the literature present a noticeable gap between the higher $p$ - and the lower $n$-values; even when limiting oneself to $\mathrm{Fe} / \mathrm{Ni}$-based antimonides skutterudites, the $\mathrm{DD}_{y}\left(\mathrm{Fe}_{x} \mathrm{Ni}_{1-x}\right)_{4} \mathrm{Sb}_{12}$ system represents an interesting example, displaying a $23 \%$ CTE mismatch between compositions with $x=0.5$ and $x=0.75$ [64]; similarly, the $\mathrm{Mm}_{y}\left(\mathrm{Fe}_{x} \mathrm{Ni}_{1-x}\right)_{4} \mathrm{Sb}_{12}$ system is characterized by a $24 \%$ CTE mismatch between the sample with $x=1$ and the one with $x=0.62$ [64]. Within this scenario, the only skutterudite system presenting $p$-and $n$-compositions with a substantially identical value of CTE is $\mathrm{Ba}_{0.09} \mathrm{Sr}_{0.02} \mathrm{DD}_{0.22} \mathrm{Yb}_{0.02} \mathrm{Fe}_{2.4} \mathrm{Ni}_{1.6} \mathrm{Sb}_{12}$ [23], even if one must take into account that the study is limited to the compositions $\mathrm{Ba}_{0.09} \mathrm{Sr}_{0.02} \mathrm{DD}_{0.22} \mathrm{Yb}_{0.02} \mathrm{Fe}_{2.4} \mathrm{Ni}_{1.6} \mathrm{Sb}_{12}$ and $\mathrm{Ba}_{0.15} \mathrm{DD}_{0.28} \mathrm{Yb}_{0.05} \mathrm{Fe}_{3} \mathrm{NiSb}_{12}$. Finally, looking in more detail at the obtained data, one can note that the CTE values of Sn-containing samples are significantly higher than the ones of the corresponding $\mathrm{Sn}$-free compositions. This result is in good agreement with the aforementioned larger size of $\mathrm{Sn}^{4-}$ than $\mathrm{Sb}^{5-}$, and it is analogous to the behavior of Sn-containing and $\mathrm{Sn}$-free samples belonging to other systems, such as the $\mathrm{Tl}_{y} \mathrm{CoSb}_{11-\delta} \mathrm{Sn}_{\delta}$ one [68]. 


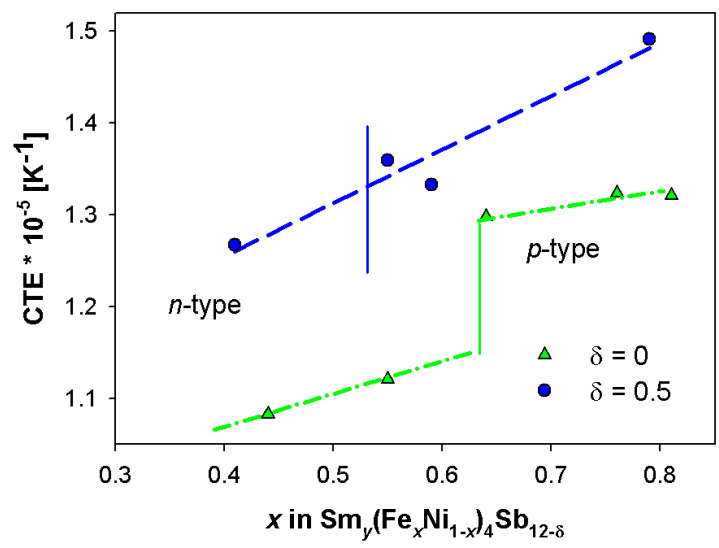

Figure 10. Trend of CTE as a function of $x$ for the $\mathrm{Sm}_{y}\left(\mathrm{Fe}_{x} \mathrm{Ni}_{1-x}\right)_{4} \mathrm{Sb}_{11.5} \mathrm{Sn}_{0.5}$ and $\mathrm{Sm}_{y}\left(\mathrm{Fe}_{x} \mathrm{Ni}_{1-x}\right)_{4} \mathrm{Sb}_{12}$ systems. The dashed blue line is a regression line, while the dash-dot green lines are guides for the eye. Vertical lines separate $n$ - from $p$-compositions for both systems; their position relies on structural data. Error bars are hidden by data markers; the data of the $\mathrm{Sm}_{y}\left(\mathrm{Fe}_{x} \mathrm{Ni}_{1-x}\right)_{4} \mathrm{Sb}_{12}$ system are taken from ref. [61].

\section{Conclusions}

A compositional and crystallographic study was performed on several samples belonging to the $\mathrm{Sm}_{y}\left(\mathrm{Fe}_{x} \mathrm{Ni}_{1-x}\right)_{4} \mathrm{Sb}_{11.5} \mathrm{Sn}_{0.5}$ system, due to its potential interest as a thermoelectric material. The composition was optimized by determining the experimental $y$ value (i.e., the Sm content) corresponding to each $x$ (i.e., the Fe content).

The crystallographic investigation performed on the filled skutterudite phase allowed us to draw the following conclusions.

- $\quad$ Relying on the refined Sm amounts, the $p / n$ crossover is expected to be located at $x \sim 0.53$, meaning that the $p$-region is enlarged with respect to the Sn-free system.

- No slope change is observed in the trend of the skutterudite cell parameter vs. $x$ in correspondence of the $p / n$ crossover at any considered temperature.

- $\quad$ A much smaller CTE mismatch is revealed between $p$ - and $n$-compositions in the present system than in the $\mathrm{Sn}$-free one, which makes $\mathrm{Sm}_{y}\left(\mathrm{Fe}_{x} \mathrm{Ni}_{1-x}\right)_{4} \mathrm{Sb}_{11.5} \mathrm{Sn}_{0.5}$ a promising thermoelectric material in terms of mechanical properties.

Supplementary Materials: The following are available online at http://www.mdpi.com/2075-4701/10/5/692/s1: Rietveld refinement plots.

Author Contributions: Conceptualization, C.A. and R.C.; methodology, C.A.; formal analysis, C.A.; investigation, L.G. and C.F.; resources, C.A. and C.F.; writing—original draft preparation, C.A.; writing-review and editing, C.A., R.C., L.G. and C.F. All authors have read and agreed to the published version of the manuscript.

Funding: This research received no external funding.

Acknowledgments: Authors are grateful to Enrico Bassani and Giordano Carcano (CNR-ICMATE Lecco) for the support in the preparation and characterization of samples. Authors also kindly acknowledge Elettra Sincrotrone Trieste for the provision of beamtime, which allowed us to collect preliminary data.

Conflicts of Interest: The authors declare no conflict of interest.

\section{References}

1. Uher, C. Skutterudite-Based Thermoelectrics. In Thermoelectrics Handbook-Macro to Nano, 1st ed.; Rowe, D.M., Ed.; Taylor and Francis: Boca Raton, FL, USA, 2005; pp. 1-17.

2. Morelli, D.T.; Meisner, G.P. Low temperature properties of the filled skutterudite $\mathrm{CeFe}_{4} \mathrm{Sb}_{12}$. J. Appl. Phys. 1995, 77, 3777. [CrossRef]

3. Nolas, G.S.; Slack, G.A.; Morelli, D.T.; Tritt, T.M.; Ehrlich, A.C. The effect of rare-earth filling on the lattice thermal conductivity of skutterudites. J. Appl. Phys. 1996, 79, 4002. [CrossRef] 
4. Rull-Bravo, M.; Moure, A.; Fernàndez, J.F.; Martìn-Gonzàlez, M. Skutterudites as thermoelectric materials: Revisited. RSC Adv. 2015, 5, 41653-41667. [CrossRef]

5. Rogl, G.; Rogl, P. Skutterudites: Progress and challenges. In Novel Thermoelectric Materials and Device Design Concepts; Skipidarov, S., Nikitin, M., Eds.; Springer: Cham/Basel, Switzerland, 2019; pp. 177-201.

6. Nazibul Hasan, M.; Wahid, H.; Nayan, N.; Sultan Mohamed Ali, M. Inorganic thermoelectric materials: A review. Int. J. Energ. Res. 2020. [CrossRef]

7. Sales, B.C. Filled skutterudites. In Handbook on the Physics and Chemistry of Rare Earths, 1st ed.; Gschneidner, K.A., Jr., Bünzli, J.-C.G., Pecharsky, V.K., Eds.; North Holland: Amsterdam, The Netherlands, 2003; Volume 33, pp. 1-34.

8. Oftedal, I. Die Kristallstruktur von Skutterudit und Speiskobalt-Chloanthit. Z. Kristallogr. A 1928, 66, 517-546. [CrossRef]

9. Toprak, M.S.; Stiewe, C.; Platzek, D.; Williams, S.; Bertini, L.; Müller, E.; Gatti, C.; Zhang, Y.; Rowe, M.; Muhammed, M. The impact of nanostructuring on the thermal conductivity of thermoelectric $\mathrm{CoSb}_{3}$. Adv. Funct. Mater. 2004, 14, 1189-1196. [CrossRef]

10. Slack, G.A. The thermal conductivity of nonmetallic crystals. In Solid State Physics; Ehrenreich, H., Seitz, F., Turnbull, D., Eds.; Academic Press: New York, NY, USA, 1979; Volume 34, pp. 1-71.

11. Kim, H.-S.; Gibbs, Z.M.; Tang, Y.; Wang, H.; Snyder, G.J. Characterization of Lorenz number with Seebeck coefficient measurement. APL Mater. 2015, 3, 041506. [CrossRef]

12. Nolas, G.S.; Takizawa, H.; Endo, T.; Sellinschegg, H.; Johnson, D.C. Thermoelectric properties of Sn-filled skutterudites. Appl. Phys. Lett. 2000, 77, 52. [CrossRef]

13. Nolas, G.S.; Yang, J.; Takizawa, H. Transport properties of germanium-filled CoSb 3 . Appl. Phys. Lett. 2004, 84, 5210. [CrossRef]

14. Li, Y.; Qiu, P.; Duan, H.; Chen, J.; Snyder, G.J.; Shi, X.; Brummerstedt Iversen, B.; Chen, L. Enhanced thermoelectric performance in rare earth-filled skutterudites. J. Mater. Chem. C 2016, 4, 4374-4379. [CrossRef]

15. Khan, A.U.; Kobayashi, K.; Tan, D.-M.; Yamauchi, Y.; Hasegawa, K.; Mitome, M.; Xue, Y.; Jiang, B.; Tsuchiya, K.; Golberg, D.; et al. Nano-micro porous skutterudites with 100\% enhancement in ZT for high performance thermoelectricity. Nano Energy 2017, 31, 152-159. [CrossRef]

16. Rogl, G.; Rogl, P. Skutterudites, a most promising group of thermoelectric materials. Curr. Opin. Green Sust. Chem. 2017, 4, 50-57. [CrossRef]

17. Benyahia, M.; Ohorodniichuk, V.; Leroy, E.; Dauscher, A.; Lenoir, B.; Alleno, E. High thermoelectric figure of merit in mesostructured $\mathrm{In}_{0.25} \mathrm{Co}_{4} \mathrm{Sb}_{12}$ n-type skutterudite. J. Alloy Compd. 2018, 73, 1096-1104. [CrossRef]

18. Rogl, G.; Rogl, P. How nanoparticles can change the figure of merit, ZT, and mechanical properties of skutterudites. Mater. Today Phys. 2017, 3, 48-69. [CrossRef]

19. Slack, G.A.; Tsoukala, V.G. Some properties of semiconducting IrSb 3 . J. Appl. Phys. 1994, 76, 1665. [CrossRef]

20. Sootsman, J.R.; Chung, D.Y.; Kanatzidis, M. New and old concepts in thermoelectric materials. Angew. Chem. Int. Edit. 2009, 48, 8616-8639. [CrossRef]

21. Mi, J.L.; Christensen, M.; Nishibori, E.; Brummerstedt Iversen, B. Multitemperature crystal structures and physical properties of the partially filled thermoelectric skutterudites $\mathrm{M}_{0.1} \mathrm{Co}_{4} \mathrm{Sb}_{12}(\mathrm{M}=\mathrm{La}, \mathrm{Ce}, \mathrm{Nd}, \mathrm{Sm}, \mathrm{Yb}$, and Eu). Phys. Rev. B 2011, 84, 064114. [CrossRef]

22. Artini, C.; Carlini, R.; Spotorno, R.; Failamani, F.; Mori, T.; Mele, P. Structural properties and thermoelectric performance of the double filled skutterudite $(\mathrm{Sm}, \mathrm{Gd})_{\mathrm{y}}\left(\mathrm{Fe}_{\mathrm{x}} \mathrm{Ni}_{1-\mathrm{x}}\right)_{4} \mathrm{Sb}_{12}$. Materials 2019, 12, 2451. [CrossRef]

23. Rogl, G.; Grytsiv, A.; Royanian, E.; Heinrich, P.; Bauer, E.; Rogl, P.; Zehetbauer, M.; Puchegger, S.; Reinecker, M.; Schranz, W. New p- and n-type skutterudites with ZT $>1$ and nearly identical thermal expansion and mechanical properties. Acta Mater. 2013, 61, 4066-4079. [CrossRef]

24. Dahal, T.; Jie, Q.; Lan, Y.; Guo, C.; Ren, Z. Thermoelectric performance of Ni compensated cerium and neodymium double filled p-type skutterudites. Phys. Chem. Chem. Phys. 2014, 16, 18170-18175. [CrossRef]

25. Yang, J.; Meisner, G.P.; Rawn, C.J.; Wang, H.; Chakoumakos, B.C.; Martin, J.; Nolas, G.S.; Pedersen, B.L.; Stalick, J.K. Low temperature transport and structural properties of misch-metal-filled skutterudites. J. Appl. Phys. 2007, 102, 083702. [CrossRef]

26. Shi, X.; Kong, H.; Li, C.-P.; Uher, C.; Yang, J.; Salvador, J.R.; Wang, H.; Chen, L.; Zhang, W. Low thermal conductivity and high thermoelectric figure of merit in n-type $\mathrm{Ba}_{\mathrm{x}} \mathrm{Yb}_{\mathrm{y}} \mathrm{Co}_{4} \mathrm{Sb}_{12}$ double-filled skutterudites. Appl. Phys. Lett. 2008, 92, 182101. [CrossRef]

27. Kaltzoglou, A.; Vaqueiro, P.; Knight, K.S.; Powell, A.V. Synthesis, characterization and physical properties of the skutterudites $\mathrm{Yb}_{\mathrm{x}} \mathrm{Fe}_{2} \mathrm{Ni}_{2} \mathrm{Sb}_{12}(0$ x 0.4). J. Solid State Chem. 2012, 193, 36-41. [CrossRef] 
28. Choi, S.; Kurosaki, K.; Ohishi, Y.; Muta, H.; Yamanaka, S. Thermoelectric properties of Tl-filled Co-free p-type skutterudites: $\mathrm{Tl}_{\mathrm{x}}(\mathrm{Fe}, \mathrm{Ni})_{4} \mathrm{Sb}_{12}$. J. Appl. Phys. 2014, 115, 023702. [CrossRef]

29. Artini, C.; Zanicchi, G.; Costa, G.A.; Carnasciali, M.M.; Fanciulli, C.; Carlini, R. Correlations between structural and electronic properties in the filled skutterudite $\mathrm{Sm}_{\mathrm{y}}\left(\mathrm{Fe}_{\mathrm{x}} \mathrm{Ni}_{1-\mathrm{x}}\right)_{4} \mathrm{Sb}_{12}$. Inorg. Chem. 2016, 55, 2574-2583. [CrossRef] [PubMed]

30. Qiu, P.F.; Liu, R.H.; Yang, J.; Shi, X.; Huang, X.Y.; Zhang, W.; Chen, L.D.; Yang, J.; Singh, D.J. Thermoelectric properties of Ni-doped $\mathrm{CeFe}_{4} \mathrm{Sb}_{12}$ skutterudites. J. Appl. Phys. 2012, 111, 023705. [CrossRef]

31. Rogl, G.; Grytsiv, A.; Falmbigl, M.; Bauer, E.; Rogl, P.; Zehetbauer, M.; Gelbstein, Y. Thermoelectric properties of $\mathrm{p}$-type didymium (DD) based skutterudites $\mathrm{DD}_{\mathrm{y}}\left(\mathrm{Fe}_{1-\mathrm{x}} \mathrm{Ni}_{\mathrm{x}}\right)_{4} \mathrm{Sb}_{12}(0.13 \leq \mathrm{x} \leq 0.25,0.46 \leq \mathrm{y} \leq 0.68)$. J. Alloy Compd. 2012, 537, 242-249. [CrossRef]

32. Rogl, G.; Grytsiv, A.; Heinrich, P.; Bauer, E.; Kumar, P.; Peranio, N.; Eibl, O.; Hork, J.; Zehetbauer, M.; Rogl, P. New bulk p-type skutterudites $\mathrm{DD}_{0.7} \mathrm{Fe}_{2.7} \mathrm{Co}_{1.3} \mathrm{Sb}_{12-\mathrm{x}} \mathrm{X}_{\mathrm{x}}(\mathrm{X}=\mathrm{Ge}, \mathrm{Sn})$ reaching $\mathrm{ZT}>$ 1.3. Acta Mater. 2015, 91, 227-238. [CrossRef]

33. Duan, F.; Zhang, L.; Dong, J.; Sakamoto, J.; Xu, B.; Li, X.; Tian, Y. Thermoelectric properties of Sn substituted p-type Nd filled skutterudites. J. Alloy Compd. 2015, 639, 68-73. [CrossRef]

34. Bérardan, B.; Alleno, E.; Godart, C.; Rouleau, O.; Rodriguez-Carvajal, J. Preparation and chemical properties of the skutterudites $(\mathrm{Ce}-\mathrm{Yb})_{\mathrm{y}} \mathrm{Fe}_{4-\mathrm{x}}(\mathrm{Co} / \mathrm{Ni})_{\mathrm{x}} \mathrm{Sb}_{12}$. Mater. Res. Bull. 2005, 40, 537-551. [CrossRef]

35. Liu, T.; Tang, X.; Xie, W.; Yan, Y.; Zhang, Q. Crystal structures and thermoelectric properties of Sm-filled skutterudite compounds $\mathrm{Sm}_{\mathrm{y}} \mathrm{Fe}_{\mathrm{x}} \mathrm{Co}_{4-\mathrm{x}} \mathrm{Sb}_{12}$. J. Rare Earth 2007, 25, 739-743.

36. Benyahia, M.; Vaney, J.B.; Leroy, E.; Rouleau, O.; Dauscher, A.; Lenoir, B.; Alleno, E. Thermoelectric properties in double-filled $\mathrm{Ce}_{0.3} \mathrm{In}_{\mathrm{y}} \mathrm{Fe}_{1.5} \mathrm{Co}_{2.5} \mathrm{Sb}_{12}$ p-type skutterudites. J. Alloy Compd. 2017, 696, 1031-1038. [CrossRef]

37. Rogl, G.; Grytsiv, A.; Rogl, P.; Bauer, E.; Zehetbauer, M. A new generation of p-type didymium skutterudites with high ZT. Intermetallics 2011, 19, 546-555. [CrossRef]

38. Alleno, E.; Zehani, E.; Gaborit, M.; Orodniichuk, V.; Lenoir, B.; Benyahia, M. Mesostructured thermoelectric $\mathrm{Co}_{1-\mathrm{y}} \mathrm{M}_{\mathrm{y}} \mathrm{Sb}_{3}(\mathrm{M}=\mathrm{Ni}, \mathrm{Pd})$ skutterudites. J. Alloy Compd. 2017, 692, 676-686. [CrossRef]

39. Trivedi, V.; Battabyal, M.; Balasubramanian, P.; Mohan Muralikrishna, G.; Kumar Jain, P.; Gopalan, R. Microstructure and doping effect on the enhancement of the thermoelectric properties of Ni doped Dy filled skutterudites. Sustain. Energ. Fuels 2018, 2, 2687-2697. [CrossRef]

40. Kong, L.; Jia, X.; Zhang, Y.; Sun, B.; Liu, B.; Liu, H.; Wang, C.; Liu, B.; Chen, J.; Ma, H. N-type $\mathrm{Ba}_{0.3} \mathrm{Ni}_{0.15} \mathrm{Co}_{3.85} \mathrm{Sb}_{12}$ skutterudite: High pressure processing technique and thermoelectric properties. J. Alloy Compd. 2018, 734, 36-42. [CrossRef]

41. Nolas, G.S.; Cohn, J.L.; Slack, G.A. Effect of partial void filling on the lattice thermal conductivity of skutterudites. Phys. Rev. B 1998, 58, 164. [CrossRef]

42. Qiu, P.; Shi, X.; Chen, X.; Huang, X.; Liu, R.; Chen, L. Effects of Sn-doping on the electrical and thermal transport properties of p-type cerium filled skutterudites. J. Alloy Compd. 2011, 509, 1101-1105. [CrossRef]

43. Shaheen, N.; Sufyan Javed, M.; Ullah Shah, H.; Hussain, S.; Ashfaq Ahmad, M.; Raza, R.; Saleem, M.; Zhou, X. Enhanced thermoelectric properties in Ge-doped and single-filled skutterudites prepared by unique melt-spinning method. Cer. Int. 2018, 44, 12610-12614. [CrossRef]

44. Zhang, L.; Duan, F.; Li, X.; Yan, X.; Hu, W.; Wang, L.; Liu, Z.; Tian, Y.; Xu, B. Intensive suppression of thermal conductivity in $\mathrm{Nd}_{0.6} \mathrm{Fe}_{2} \mathrm{Co}_{2} \mathrm{Sb}_{12-x} \mathrm{Ge}_{\mathrm{x}}$ through spontaneous precipitates. J. Appl. Phys. 2013, 114, 083715. [CrossRef]

45. Lei, Y.; Gao, W.; Li, Y.; Wan, R.; Chen, W.; Zheng, R.; Ma, L.; Zhou, H. Structure and thermoelectric performance of Ti-filled and Te-doped skutterudite $\mathrm{Ti}_{\mathrm{x}} \mathrm{Co}_{4} \mathrm{Sb}_{11.5} \mathrm{Te}_{0.5}$ bulks fabricated by combination of microwave synthesis and spark plasma sintering. Mater. Lett. 2018, 233, 166-169. [CrossRef]

46. Dong, J.; Yang, K.; Xu, B.; Zhang, L.; Zhang, Q.; Tian, Y. Structure and thermoelectric properties of Se- and $\mathrm{Se} / \mathrm{Te}$-doped $\mathrm{CoSb}_{3}$ skutterudites synthesized by high-pressure technique. J. Alloy Compd. 2015, 647, $295-302$. [CrossRef]

47. Duan, B.; Zhai, P.; Liu, L.; Zhang, Q. Enhanced thermoelectric performance in sulfur-doped $\mathrm{Co}_{4} \mathrm{Sb}_{11.9-\mathrm{x}} \mathrm{Te}_{\mathrm{x}} \mathrm{S}_{0.1}$ skutterudites. Mater. Lett. 2012, 79, 69-71. [CrossRef]

48. Sun, H.; Jia, X.; Deng, L.; Wang, C.; Lv, P.; Guo, X.; Sun, B.; Zhang, Y.; Liu, B.; Ma, H. Beneficial effect of high pressure and double-atom-doped skutterudite compounds $\mathrm{Co}_{4} \mathrm{Sb}_{11.5-\mathrm{x}} \mathrm{Te}_{0.5} \mathrm{Sn}_{\mathrm{x}}$ by HPHT. J. Alloy Compd. 2014, 612, 16-19. [CrossRef] 
49. Hui, S.; Nielsen, M.D.; Homer, M.R.; Medlin, D.L.; Tobola, J.; Salvador, J.R.; Heremans, J.P.; Pipe, K.P.; Uher, C. Influence of substituting $\mathrm{Sn}$ for $\mathrm{Sb}$ on the thermoelectric transport properties of $\mathrm{CoSb}_{3}$-based skutterudites. J. Appl. Phys. 2014, 115, 103704. [CrossRef]

50. Chakoumakos, B.C.; Sales, B.C. Skutterudites: Their structural response to filling. J. Alloy Compd. 2006, 407, 87-93. [CrossRef]

51. Phuangyod, A.; Hayashi, J.; Kawamura, Y.; Artini, C.; Latronico, G.; Carlini, R.; Saini, S.; Mele, P.; Sekine, C. Thermoelectric properties of p-type and n-type filled skutterudite compounds $\mathrm{Sm}_{\mathrm{y}}\left(\mathrm{Fe}_{\mathrm{x}} \mathrm{Ni}_{1-\mathrm{x}}\right)_{4} \mathrm{Sb}_{12}$ prepared under high pressure. Jpn. J. Appl. Phys. 2020, 59, 061004. [CrossRef]

52. Kim, I.-H.; Park, K.-H.; Ur, S.-C. Thermoelectric properties of Sn-doped $\mathrm{CoSb}_{3}$ prepared by encapsulated induction melting. J. Alloy Compd. 2007, 442, 351-354. [CrossRef]

53. Artini, C.; Carlini, R. Influence of composition and thermal treatments on microhardness of the filled skutterudite $\mathrm{Sm}_{\mathrm{y}}\left(\mathrm{Fe}_{\mathrm{x}} \mathrm{Ni}_{1-\mathrm{x}}\right)_{4} \mathrm{Sb}_{12}$. J. Nanosci. Nanotechnol. 2017, 17, 1634-1639. [CrossRef]

54. Artini, C.; Castellero, A.; Baricco, M.; Buscaglia, M.T.; Carlini, R. Structure, microstructure and microhardness of rapidly solidified $\mathrm{Sm}_{\mathrm{y}}\left(\mathrm{Fe}_{\mathrm{x}} \mathrm{Ni}_{1-\mathrm{x}}\right)_{4} \mathrm{Sb}_{12}(\mathrm{x}=0.45,0.50,0.70,1)$ thermoelectric compounds. Solid State Sci. 2018, 79, 71-78. [CrossRef]

55. Artini, C.; Parodi, N.; Latronico, G.; Carlini, R. Formation and decomposition process of the filled skutterudite $\mathrm{Sm}_{\mathrm{y}}\left(\mathrm{Fe}_{\mathrm{x}} \mathrm{Ni}_{1-\mathrm{x}}\right)_{4} \mathrm{Sb}_{12}(0.40 \leq \mathrm{x} \leq 1)$ as revealed by differential thermal analysis. J. Mater. Eng. Perform. 2018, 27, 6259-6265. [CrossRef]

56. Carlini, R.; Parodi, N.; Soggia, F.; Latronico, G.; Carnasciali, M.; Artini, C. Corrosion behavior of $\mathrm{Sm}_{\mathrm{y}}\left(\mathrm{Fe}_{\mathrm{x}} \mathrm{Ni}_{1-\mathrm{x}}\right)_{4} \mathrm{Sb}_{12}(0.40 \leq \mathrm{x} \leq 0.80)$ in sodium chloride solutions studied by electron microscopy and ICP-AES. J. Mater. Eng. Perform. 2018, 27, 6266-6273. [CrossRef]

57. Spotorno, R.; Ghiara, G.; Carlini, R.; Latronico, G.; Mele, P.; Artini, C. Corrosion of the filled skutterudite $\mathrm{Sm}_{\mathrm{y}}\left(\mathrm{Fe}_{\mathrm{x}} \mathrm{Ni}_{1-\mathrm{x}}\right)_{4} \mathrm{Sb}_{12}(\mathrm{x}=0.40,0.80)$ by NaCl solutions: An electrochemical study. J. Electron. Mater. 2020, 49, 2872-2880. [CrossRef]

58. Latronico, G.; Valenza, F.; Carlini, R.; Mele, P.; Artini, C. Interfacial reactivity of the filled skutterudite $\mathrm{Sm}_{\mathrm{y}}\left(\mathrm{Fe}_{\mathrm{x}} \mathrm{Ni}_{1-\mathrm{x}}\right)_{4} \mathrm{Sb}_{12}$ in contact with liquid In-based alloys and Sn. Metals 2020, 10, 364. [CrossRef]

59. Artini, C.; Latronico, G.; Carlini, R.; Saini, S.; Takeuchi, T.; Choi, S.; Baldini, A.; Anselmi-Tamburini, U.; Valenza, F.; Mele, P. Effect of different processing routes on the power factor of the filled skutterudite $\mathrm{Sm}_{\mathrm{y}}\left(\mathrm{Fe}_{\mathrm{x}} \mathrm{Ni}_{1-\mathrm{x}}\right)_{4} \mathrm{Sb}_{12}(\mathrm{x}=0.50-0.80 ; \mathrm{y}=0.12-0.53)$. ES Mater. Manuf. 2019, 5, 29-37. [CrossRef]

60. Artini, C.; Cingolani, A.; Anselmi Tamburini, U.; Valenza; Latronico, G.; Mele, P. Effect of sintering parameters on structure and microstructure of the filled skutterudite $\mathrm{Sm}_{\mathrm{y}}\left(\mathrm{Fe}_{\mathrm{x}} \mathrm{Ni}_{1-\mathrm{x}}\right)_{4} \mathrm{Sb}_{12}$. Mater. Res. Bull.. submitted.

61. Artini, C.; Fanciulli, C.; Zanicchi, G.; Costa, G.; Carlini, R. Thermal expansion and high temperature structural features of the filled skutterudite $\mathrm{Sm}_{\beta}\left(\mathrm{Fe}_{\alpha} \mathrm{Ni}_{1-\alpha}\right)_{4} \mathrm{Sb}_{12}$. Intermetallics 2017, 87, 31-37. [CrossRef]

62. Carlini, R.; Ullah Khan, A.; Ricciardi, R.; Mori, T.; Zanicchi, G. Synthesis, characterization and thermoelectric properties of $\mathrm{Sm}$ filled $\mathrm{Fe}_{4-\mathrm{x}} \mathrm{Ni}_{\mathrm{x}} \mathrm{Sb}_{12}$ skutterudites. J. Alloy Compd. 2016, 655, 321-326. [CrossRef]

63. Uher, $\mathrm{C}$. In search of efficient n-type skutterudite thermoelectrics. In Twenty-First International Conference on Thermoelectrics, Proceedings of the 21st Conference on Thermoelectrics, Long Beach, CA, USA, 29 August 2002; IEEE: New York, NY, USA, 2002; pp. 35-41.

64. Rogl, G.; Zhang, L.; Rogl, P.; Grytsiv, A.; Falmbigl, M.; Rajs, D.; Kriegisch, M.; Müller, H.; Bauer, E.; Koppensteiner, J.; et al. Thermal expansion of skutterudites. J. Appl. Phys. 2010, 107, 043507. [CrossRef]

65. Rogl, G.; Bursik, J.; Grytsiv, A.; Puchegger, S.; Soprunyuk, V.; Schranz, W.; Yan, X.; Bauer, E.; Rogl, P. Nanostructuring as a tool to adjust thermal expansion in high ZT skutterudites. Acta Mater. 2018, 145, 359-368. [CrossRef]

66. Rodriguez-Carvajal, J. Recent advances in magnetic structure determination by neutron powder diffraction. Physica B 1993, 192, 55-69. [CrossRef] 
67. Singh, H.P. Determination of thermal expansion of germanium, rhodium and iridium by X-rays. Acta Cryst. A 1968, 24, 469-471. [CrossRef]

68. Chakoumakos, B.C.; Sales, B.C.; Mandrus, D.; Keppens, V. Disparate atomic displacements in skutterudite-type $\mathrm{LaFe}_{3} \mathrm{CoSb}_{12}$, a model for thermoelectric behaviour. Acta Cryst. B 1999, 55, 341-347. [CrossRef] [PubMed] 